\title{
Individuated Media in the Informational Era
}

\author{
Vin Crosbie \\ Syracuse University
}

As the Industrial Era wanes and the Informational Era dawns, a new genus of media has arisen from the unprecedented capabilities of computer-mediated technologies to provide simultaneously to massive numbers of consumers individualized selections of news stories, entertainment, and other information, according to each consumer's own unique mix of needs, interests, tastes, and beliefs. This genus, which this paper terms Individuated Media, has reach equal or exceeding that of the Industrial Era media products and services colloquially known as Mass Media; yet can be differentiated from such traditional media because each consumer simultaneously receives a customized, even bespoke, feed of contents, unlike the uniform edition or program schedule that the consumers of a Mass Media service would all simultaneously receive. This paper considers recognizing Individuated Media as a distinctly new genus of media and begins to examine this new media's affects upon the sustainability of traditional media theories, doctrines, practices, and business models in this century.

Keywords: mass media, individuated media, online media, digital media, computer-mediated

\section{INTRODUCTION}

This paper proposes that what might be termed a new genus of media has arisen during the past 20 years due to the introduction of computer-mediated algorithmic technologies into the media environment; that this evolution has caused pronounced changes in that environment; and that this evolutionary change necessitates reappraisals and critiques of some theories, doctrines, practices, and business models which arose during the previous centuries from Industrial Era media technologies and that gave rise to the legacy genera of media which have become colloquially known as Mass Media. This new genus of media has the mass reach and mass production abilities of Mass Media, yet can be clearly differentiated from Mass Media due to its novel abilities to aggregate and on mass scale customize the selection of contents each of its consumers receives according to that individual consumer's own expressed, detected, or computerpredictable individual mix of needs, interests, tastes, beliefs, and behaviors, rather than more simply upon mass demographics such as age, gender, and location.

Among the many forms this new genus of media manifests are search engines, social media, and computer-mediated genre- or format-specific services such as Pandora, Netflix, Spotify, YouKu, and the recently defunct Xiami. The term "Individuated Media" to describe categories of such services was coined by news publishing industry executives who in Leipzig convened the first Personalized MEdia conference (Vandevanter, 2007) to discuss the commercial potentials and production and editorial ramifications of this then-emergent genus of media ${ }^{1}$. These algorithmically computer-mediated services can provide to each consumer a highly customized or even individuated (i.e., bespoke) selections of news, entertainment, or 
other information, which might better match that individual consumer's unique mix of needs, interests, tastes, and beliefs, better than can the traditional products or services of any Mass Media company and from a greater aggregated range of content sources. Extremely competitive when competing against Mass Media products and services, Individuated Media have experienced explosive growth in the media environment, within two decades becoming the predominant means by which most adults above age 30 in developed nations nowadays obtain news, entertainment, and other information (Auxier \& Andereson, 2021).

Understanding the nature of Individuated Media, the challenges that these new media create to the world's legacy Mass Media industries, and how the media environment might ultimately adapt to this genesis is of existential importance to the financial viability of media industries. Nowhere has that become of greater import than in the general-interest journalism sector and in the commercial television sector of

Mass Media. The former sector has suffered grave circulatory and financial damages due to the rise of Individuated Media drawing away its consumer and advertiser clientele, and the latter sector might be in the onset of such a conflict.

\section{Mistaken Assumptions by Mass Media Industries}

Newspapers during the late 1970s through the mid-1990s were the first sector of the Mass Media industries to encounter computer-mediated (i.e., online; often colloquially, if sometimes erroneously, known as "digital") technologies. Consumers' online access technologies during this period required connecting a modem to a home or office telephone line operating at baud rates that could transmit texts but were not fast enough for audio or video contents. Newspapers began experimenting online by hosting their contents on third-party proprietary online services such as CompuServe, Prodigy, America Online, etc., Each of these proprietary services used a "walled-garden" business model to deliver the contents to that service's own subscribers, paying the newspapers a royalty time apportioned from the services' monthly subscription fees. The invention of the open source World Wide Web and opening of the Internet to businesses and consumers during the early 1990s undercut those proprietary online services sinecures, allowing media companies to host their own contents online and interface directly with consumers on the Internet. The later invention of multimedia Web browsing software then facilitated consumers' access to a multimedia combination of texts, still imagery, and some basic graphical layout, fostering usage of newspaper and magazine contents online. During 1996, the San Jose Mercury News of California became the first daily newspaper to begin publishing via the Web. Virtually every major daily newspaper in developed countries was publishing online that way by 2000 .

According to proceedings of newspaper and magazine industry conferences convened about online during the 1990s and opening years of the 2000s (Crosbie \& Jansen, 2007), most journalist, media academician, and media executives assumed that consumers would utilize the same behaviors (i.e., frequency, depth, and engagement) regarding online forms of periodicals that consumers had used with similar contents in printed editions. Popular catch phrases among Mass Media executives assigned to online, many of whose experiences with online dated from limited experiments with teletext systems during the 1970 or the commercial experiments with proprietary online services during the 1980s and early 1990s, were that consumers were now becoming 'hooked-up' or 'wired'. Consequently, those executives employed their media companies' websites as wired-mediated technologies, in which consumers' personal computers would be used as teletext-like response terminals to retrieve those media companies' Mass Media packaged contents transplanted online. These executives likewise assumed that the Mass Media business models that worked with printed periodicals, from which the contents came, would thus work when those contents were put online. Mass Media executives in general hoped that the global reach of online might bring their companies' services wider reaches to consumers and from advertisers than periodical delivery trucks, postal mailings, or terrestrial broadcast antennae or cable television systems could. They similarly hoped that as more consumers shifted media consumption to online, this new form of distribution might ultimately increase their profits by eliminating their expenses of purchasing, printing, and distributing paper for periodicals; circumventing the expensive contractual bottlenecks involved in cable or satellite distribution of broadcasts; and sidestepping some governmental anti-monopoly or content regulations involving broadcasting. Most Mass Media executives professed that their legacy printing or 
broadcasting operations would continue operating viably into and throughout the $21^{\text {st }}$ Century, but they anticipated that online operations would be an adjunct source of revenues that might possibly equal those legacy operations' revenues as the century continued.

What the most Mass Media executives assigned to online operations failed to foresee was that rapid consumer adoption of the World Wide Web, combined with the introduction of broadband technologies, would lead consumers to consume contents online differently than that had similar contents in legacy Mass Media. As business author Evan Schwartz presciently noted in his 1997 book, Webonomics:

You can already see it happening right before your eyes. Once they enter the Web economy, all magazines and newspapers that you hold in your hands deconstruct - in the true sense of the word. They lose their unity. They break up or decompose into their constituent elements. No longer is the editorial product a cohesive package tightly controlled by a team of editors. Once on the $\mathrm{Web}$, the editors must relinquish some of that control to the readers, who play a big part in reinventing and reinterpreting how that information is seen. Instead of flipping through pages in a linear fashion, readers may pick and choose from menus of stories, look up stock quotes, search databases of classified ads, and have conversations with editors and other readers. They may never even see what the editors deem the top story of the day." (Schwartz, 1997, pp. 33-34)

Due to the Internet giving them access to most of the world's periodicals rather than just the printed ones that were available at local kiosk or delivered to their doorsteps or postal mailboxes, consumers now could as easily choose to access instead the websites of more topically specialized periodicals to which they had never previously had access. For instances, a consumer interested in golf news could now access Golf magazine's website, updated daily, rather than read the sports sections of his local daily newspaper or its website. Or a consumer interested in finance could now easily access the websites of The Wall Street Journal or Financial Times rather than read the coverage of finance in his local daily newspaper or its website. The only major reason why those consumers might read their local daily newspaper or its website was for the only type of news it published for which none other of the world's websites specialized: the local news. Ten years after Schwartz's noted how the traditional Mass Media package of general-interest contents from the daily newspaper's printed edition 'unbundled' when placed online, Peter Horrocks, the director of the British Broadcasting Corporations World Services wrote about how most major news organizations still did not understand this:

"The consequence of this change in users' consumption has only dimly been understood by the majority of journalists. Most of the major news organisations had the assumption that their news product provided the complete set of news requirements for their users. But in an internet world, users see the total information set available on the web as their 'news universe'. I might like BBC for video news, the Telegraph or Daily Mail for sports results and the New York Times for international news. The ability of audiences to pull together their preferred news is bringing the walls of the fortresses tumbling down. In effect, the users see a single unified news universe and uses technology (e.g. Google, Digg, etc.) to get that content to come together. Thus, if media companies simply transplant into digital their traditional packages of content-even with the converged additions of hyperlinks, multimedia, editors' or CEO's blogs, and 'hyperlocal' coverage-and offer these enhanced traditional packages content via Web sites, mobile phones, and e-book devices, the companies will fail." (Horrocks, The End of Fortress Journalism, 2009)

Yet around that time data was showing the results of this for major daily newspapers. Those periodicals discovered that although online publishing was gaining them significantly more 'Unique Monthly Users' than these newspapers had daily printed circulations, consumers online used the periodicals' contents less frequently, less deeply, and with less engagement than consumers who used the same contents in print. For 
example, an analysis during 2007 by the Nielsen//NetRatings media analytics agency about major U.S. daily newspaper websites, presented here as Table 1, reports that the average user among the nearly 14 million Monthly Unique Users then of The New York Times website visited that website only 4.05 times per month - a frequently roughly equivalent to once per week; saw a total of only 27 webpages ${ }^{2}$ during those visits; and spent an aggregate total of less than 21 minutes per month on the website. Less prestigious U.S. newspapers fared worse. At the request of the U.S. newspaper industry in 2010, Nielsen, ComScore, and other analytics agencies ceased publicly publishing such analytics.

Although most Mass Media executives assigned to online had assumed that advertising online functioned according to the same business models as printed advertising did, most had overlooked that online advertisers are charged only for the number of advertisements are actually exposed to consumers, a number which the interactivity of online can tally, rather than a rate based upon the entire paid circulation of a periodical (or an estimate of the broadcast's listenership or viewership) as traditional in Mass Media. So, if the average consumer of a daily newspaper's website visits it approximately only once per week (i.e., 4.05 times per month), then that newspaper's website can generate advertising from is visitation just oneseventh as often as that newspaper could from a consumer who daily purchased or subscribed to its printed edition.

Furthermore, print and broadcast advertising rates are mainly based upon the economics of scarcity: there are a finite number of pages in a printed edition or a finite number of minutes in a broadcast hour. For example, if a printed periodical's circulation were to double, its publisher need not print double the number of pages in subsequent editions; he will likely continue to print the same number of pages per edition but can now increase, perhaps double, the cost per thousand (CPM) that he charges advertisers per page of advertising. However, online operates according to the economics of surplus: if a website's number of Monthly Unique Users were to double, its publisher need not subsequently double the number of webpages on that site; he must instead find purchasers for double the inventory of online ads that he had been previously exposing to Monthly Unique Users. If the publisher cannot find advertisers willing to purchase a double the number of online ads, then the CPM rate that he had been charging advertisers will decline because he will then have to expose webpages without advertising or else run free additional exposures of the advertisements for which he has purchasers. Thus, as increasing numbers of consumers shifted their media consumption habits from print to online during the past 20 years, these larger audiences for Mass Media websites did not axiomatically lead to increases in advertising CPMs for those websites, but instead tended to dampen or decrease the CPMs. Making that situation worse, as an increasing number of advertising-supported websites were launched, including those by social media, bloggers, etc., that further increased the advertising inventory available to advertisers, further dampening or depressing the advertising CPM rates sites could charge and puncturing most Mass Media executives' expectations that online might generate revenues equal or greater than they had earned from print or broadcast.

As for the traditional business model of charging consumers to read or view contents, if the average Monthly Unique User of a Mass Media website uses it infrequently and shallowly when he can access it for free, how likely is that consumer to pay to access it? During 2010, The New York Times started charging for unlimited access to its website (Peters, 2011). It initially allowed its website's users free access to ten stories per month, a number it reduced during 2017 to five. Now, after ten years of marketing online subscriptions through its online 'paywall', that newspaper has been able to convert to subscribers only 3.4 million of its website's now 120 million registered Monthly Unique Users (The New York Times Company 2020 Annual Report, 2021). Another 1 million have subscribed only to recipes or crossword puzzles, but not access to the newspaper's news coverage. That conversion rate is 2.8 percent ( 3.7 percent if recipe and crossword puzzle subscribers are included), which after ten years is not markedly better than the 2 percent subscription conversion rate (Noam, 2018) that a one-time direct mail marketing campaign by a newspaper or magazine to consumers might have gained. In this endeavor, too, less renowned U.S. daily newspapers have fared no better (Chyi \& Ng, 2020). 
TABLE 1

LONG TAIL

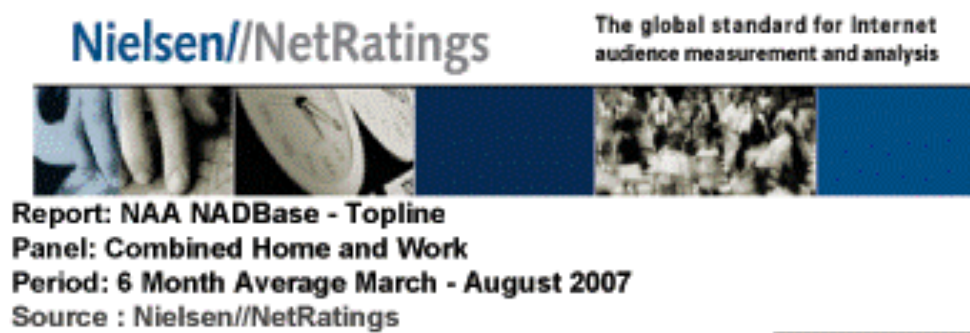

Source : Nielsen//NetRatings

\begin{tabular}{|c|c|c|c|c|c|c|}
\hline & & \multicolumn{5}{|c|}{6 Month Average Metrics (March - August 2007) } \\
\hline UV Rank & Category & $\begin{array}{c}\text { Unique } \\
\text { Visitors } \\
(000)\end{array}$ & $\begin{array}{c}\text { Web Page } \\
\text { Views (000) }\end{array}$ & $\begin{array}{c}\text { Web } \\
\text { Pages } \\
\text { Per } \\
\text { Visitor }\end{array}$ & $\begin{array}{c}\text { Visits Per } \\
\text { Visitor }\end{array}$ & $\begin{array}{c}\text { Time Per } \\
\text { Visitor } \\
\text { (hh:mm:ss) }\end{array}$ \\
\hline 1 & New York Times & 13,857 & 370,200 & 27 & 4.05 & $0: 20: 20$ \\
\hline 2 & Washington Post, The & 11,682 & 190,997 & 16 & 3.20 & $0: 14: 14$ \\
\hline 3 & USA Today & 9,186 & 110,331 & 12 & 2.85 & $0: 10: 57$ \\
\hline 4 & Wall Street Journal & 8,337 & 163,057 & 20 & 3.92 & $0: 09: 55$ \\
\hline 5 & Los Angeles Times & 4,992 & 75,758 & 15 & 2.53 & $0: 12: 34$ \\
\hline 6 & Boston Globe & 3,798 & 73,560 & 19 & 3.22 & $0: 14: 19$ \\
\hline 7 & San Francisco Chronicle & 3,653 & 30,386 & 8 & 2.26 & $0: 04: 55$ \\
\hline 8 & Chicago Tribune & 3,316 & 61,733 & 19 & 3.17 & $0: 11: 46$ \\
\hline 9 & New York Post & 2,895 & 42,071 & 15 & 2.52 & $0: 06: 47$ \\
\hline 10 & Seattle Times/Post-Intelligencer & 2,838 & 43,684 & 15 & 3.40 & $0: 14: 54$ \\
\hline 11 & Houston Chronicle, The & 2,520 & 43,961 & 18 & 2.83 & $0: 12: 53$ \\
\hline 12 & Atlanta Journal-Constitution & 2,448 & 80,297 & 34 & 3.45 & $0: 18: 19$ \\
\hline 13 & Orlando Sentinel, The & 2,153 & 20,650 & 13 & 2.86 & $0: 10: 22$ \\
\hline 14 & Phoenix: Arizona Republic & 2,150 & 45,212 & 21 & 2.92 & $0: 08: 35$ \\
\hline 15 & New York: Newsday & 2,065 & 30,724 & 15 & 2.38 & $0: 06: 57$ \\
\hline 16 & New York Daily News & 1,979 & 26,161 & 14 & 2.60 & $0: 11: 00$ \\
\hline 17 & San Diego Union-Tribune, The & 1,643 & 14,589 & 9 & 2.22 & $0: 07: 09$ \\
\hline 18 & Philadelphia Inquirer/News & 1,620 & 30,663 & 19 & 3.99 & $0: 15: 05$ \\
\hline 19 & Dallas Morning News & 1,530 & 19,961 & 13 & 2.52 & $0: 08: 00$ \\
\hline 20 & Pittsburgh Post-Gazette & 1,461 & 50,397 & 35 & 6.40 & $0: 30: 34$ \\
\hline 21 & Newark Star Ledger (nj.com) & 1,389 & 44,748 & 33 & 3.00 & $0: 14: 46$ \\
\hline 22 & Minneapolis Star Tribune & 1,325 & 25,850 & 19 & 3.43 & $0: 12: 43$ \\
\hline 23 & San Jose Mercury News & 1,250 & 16,980 & 14 & 2.95 & $0: 10: 05$ \\
\hline 24 & St. Petersburg Times & 1,232 & 11,716 & 9 & 3.66 & $0: 07: 33$ \\
\hline 25 & Detroit Free Press & 1,204 & 12,466 & 10 & 2.85 & $0: 11: 45$ \\
\hline 26 & Sun-Sentinel & 1,203 & 16,377 & 14 & 2.46 & $0: 07: 31$ \\
\hline 27 & Orange County Register & 1,163 & 13,716 & 12 & 2.08 & $0: 05: 20$ \\
\hline 28 & Miami Herald & 1,127 & 8,992 & 8 & 2.09 & $0: 06: 06$ \\
\hline 29 & Las Vegas Review Journal & 1,034 & 9,882 & 10 & 1.77 & $0: 06: 22$ \\
\hline 30 & Cincinnati Enquirer, The & 1,025 & 25,899 & 25 & 3.30 & $0: 14: 38$ \\
\hline 31 & Kansas City Star, The & 1,005 & 9,841 & 10 & 2.11 & $0: 07: 01$ \\
\hline 32 & Cleveland: Plain Dealer & 989 & 22,424 & 23 & 2.34 & $0: 10: 55$ \\
\hline 33 & Washington Times, The & 982 & 10,437 & 11 & 2.88 & $0: 10: 13$ \\
\hline 34 & Detroit News, The & 976 & 11,574 & 12 & 2.71 & $0: 13: 22$ \\
\hline 35 & Indianapolis Star, The & 962 & 17,800 & 19 & 3.75 & $0: 14: 03$ \\
\hline 36 & Grand Rapids Press (mlive.com) & 958 & 23,116 & 24 & 2.32 & $0: 11: 52$ \\
\hline 37 & Boston Herald & 957 & 21,103 & 22 & 4.11 & $0: 18: 45$ \\
\hline 38 & Milwaukee Journal Sentinel & 954 & 20,720 & 21 & 5.04 & $0: 19: 53$ \\
\hline 39 & Baltimore Sun & 939 & 13,889 & 15 & 2.84 & $0: 10: 57$ \\
\hline 40 & St. Louis Post-Dispatch & 910 & 58,931 & 64 & 5.58 & $0: 29: 54$ \\
\hline 41 & Denver Post, The & 893 & 16,992 & 19 & 2.86 & $0: 13: 41$ \\
\hline 42 & Tampa Tribune & 866 & 11,023 & 13 & 3.25 & $0: 08: 32$ \\
\hline 43 & Austin-American Statesman & 861 & 14,596 & 17 & 2.43 & $0: 10: 23$ \\
\hline 44 & Sacramento Bee. The & 799 & 15.860 & 20 & 2.98 & $0: 11: 27$ \\
\hline
\end{tabular}


A result of these myopic assumptions by Mass Media executives about computer-media technologies has been that as consumers have shifted their media consumption habits from print to online, that nation's daily newspaper industry's annual gross revenues from its printed editions plunged during the past 15 years from $\$ 42$ billion to less than $\$ 19$ billion, erasing more than 50 years of annual gains. Meanwhile. that industry's gross revenues from online grew to only $\$ 3$ billion annually, hardly compensating for the printed editions' \$23 billion net annual loss. And Google and Facebook, two Individuated Media companies, now control 60 percent of all online advertising including slightly more than 50 percent of all local online advertising, in the U.S. (News Media Alliance, 2020). The local commercial television industry in the U.S. might be experiencing the start of a similar decline as millions of its consumers are shifting their television media consumption from local over-the-air or cable television channels and to Internet-based 'Over-TheTop' on-demand or live streaming from Individuated Media services such as Netflix, YouTube, Roko, etc.

\section{Breaching A Hallmark Limitation}

The theories, doctrines, practices, and business models of Mass Media arose from the Industrial Era's media technologies. Although there might be debate about when the Industrial Era began, with many academicians tending to fix that date to the development of waterpower or a practical steam engine, this author proposes for media purposes that it began with the invention by Johannes Gutenberg circa 1450 of a practical moveable-type printing press, a device that could mass produced books or periodicals which could then be mass distributed. Guglielmo Marconi's invention of a practical analog waveform transmitter some 450 years later, which led to the development of radio and television, enhanced that with instantaneous reach and multimedia forms. The genera of media now known as Mass Media were engendered from those analog major media technologies, as were the theories, doctrines, practices, and business models practices of Mass Media. However, all analog media technologies have at their core a hallmark limitation: the inability to create a unique package of contents for each consumer according to that individual's own unique mix of needs, interests, tastes, and beliefs. As a result of this limitation, all recipients of a Mass Media package of contents (an edition, a program schedule, a playlist, etc.) in general simultaneously receives the same selection of items as every other recipient of that package. Many of Mass Media's theories, doctrines, practices, and business models are rooted in this limitation and the analog uniformity it produces. For examples, due to this limitation of Mass Media, most editors of news periodicals or producers of news broadcasts utilize two criteria when selecting which items to include in the editions or broadcasts that they produce: (1) items about which they think everyone should become informed and/or (2) items which might have the greatest common demographic interest. Publishers or broadcasters of entertainments often use solely the second criterium. Yet no matter how skilled those producers or editors might be, surveys of consumers perennially indicate that all or many, if not the majority, of items selected in each edition or program schedule don't interest the average recipient; only a few of the items do, and which items do will vary among individuals.

That hallmark limitation of Industrial Era analog technologies does not exist with the Informational Era's computer-mediated technologies ${ }^{3}$. Online media have equal or greater reach than analog media technologies do yet are inherently capable of producing and distributing a unique selection of contents (an individualized edition, an individualized stream of video programs, an individualized music playlist, etc.) for each consumer according to that individual's consumers own expressed, recorded, or live online mix of needs, interests, tastes, and beliefs.

Consider the following thought experiment. Imagine that throughout your life you had been served whatever meal that everyone else in your community was served that day, yet you now have been given access to the largest buffet of food in the world. Would you choose to continue consuming the standard meals that you have been given? Or would you instead select from the gargantuan buffet whatever mix of items you choose to match your own unique mix of needs, interests, and tastes? If you are like billions of online consumers who nowadays seek news, entertainment, and other information, you'll choose to use the buffet and will reduce or cease your consumption of the standard meal. This is akin to how media consumption has fundamentally changed now that most consumers' supply and choices of, news, entertainment, and other information, has shifted from relative scarcity to surplus and even overload during 
the past 20 years as the Industrial Era wanes and the Informational Era dawns. Rather than each consumer continuing to pay to consume a common selection of news, entertainment, or other information, which is selected and packaged according to Industrial Era doctrines and practices, in Mass Media companies' hopes that this demographically uniform selection of contents might satisfy the most consumers' needs, interests, tastes, the consumer himself is using his web browser or algorithmic software applications, via his personal computer and smartphone, to gain a better selection of content than he has been able to get from Mass Media companies.

During the early 1990s, pioneers among consumers manually hunted and gathered such selections by using their web browser software and bookmarking the websites of interest they found them. By the mid1990s, website indexing applications, called search engines, were developed that greatly aided millions of consumers' efforts to hunt and gather such selections. To make subsequent searches more efficient, these search engines also recorded the consumer's previous searches and which of those results the consumers had selected, creating a computerized profile of that consumer's needs, interests, and tastes. During the first decade of the new century, tens of millions of consumers soon discovered other websites that contained algorithmic software engines which connected consumers not only with their friends who might also use that software but also contents providers who chose to. This allowed consumers to begin receiving automatic feeds of not only posting by those friends but also abstracts and hyperlinks to news, entertainment, other information, and advertising from the contents producers to who the consumer expressed a 'Like' or a 'Follow', his network of presumably like-minded friends expressed a 'Like' or 'Follow', or which the software suggested. Among websites hosting such software applications are Facebook, Twitter, Renren, Vkontakte, Sina Weibo, etc., services that have colloquially become known as social media. In recent years, several companies have launched websites whose algorithmic software engines select and individuate feeds of genre-specific entertainment content, such as Netflix for videos and Pandora and Spotify for music. All these search engines, social media, and genre-specific Individuated Media services also individuate advertising to consumers based upon the consumer's history of content selections, online behavior, or algorithmically calculated demographic and interest profile. As Moore's Law of transistors, Cooper's Law of wireless, Butters's Law of photonics, and their interactions are advancing computer-mediated power exponentially and given the rise of Machine Learning and Artificial Intelligence, perhaps aided by developments in Quantum Computer, it appears likely that the continued development of even more powerful and articulate content algorithmic individuation engines will occur.

The fulminant growth and success of these Individuated Media companies during the past 20 years took most Mass Media companies by surprise. Facebook, with 2.8 billion monthly active users, 1.84 billion of whom use it daily (Facebook Inc., 2021), has more users than China Central Television (CCTV), the world's largest Mass Media company; yet unlike CCTV each of its billions of users simultaneously sees a different selection of contents than does any other of its users. Even Spotify, a company only 13 years old, has 345 million Monthly Unique Users, of whom 155 million pay a monthly subscription fee for fully individuated services (Spotify Inc., 2021). Even though Individuated Media services didn't exist 30 years ago, approximately 3.7 billion people worldwide, half of humanity, nowadays use them (Dean, 2021).

Twenty-six years ago, routine usage of Individuated Media was predicted by MIT Media Lab Director Nicholas Negroponte in his book, Being Digital:

"Imagine a future in which your interface agent can read every newswire and newspaper and catch every TV and radio broadcast on the planet, and then construct a personalized summary, This kind of newspaper is printed in an edition of one. ... You would consumer every bit (so to speak). Call it The Daily Me." (Negroponte, 1995)

That there might be a ready market for selections of contents that weren't based upon general demographics but upon the myriad idiosyncrasies of individual consumers' needs, interests, tastes, and beliefs, was prevised by editor-in-chief of Wired magazine Chris Anderson in his 2006 book, The Long Tail: Why the Future of Business Is Selling Less of More: 
"The theory of the Long Tail is that our culture and economy is increasingly shifting away from a focus on a relatively small number of "hits" (mainstream products and markets) at the head of the demand curve and toward a huge number of niches in the tail. As the costs of production and distribution fall, especially online, there is now less need to lump products and consumers into one-size-fits-all containers. In an era without the constraints of physical shelf space and other bottlenecks of distribution, narrowly targeted goods and services can be as economically attractive as mainstream fare. " (Anderson, The Long Tail in a Nutshell, n.d.)

Anderson found that this concept could be displayed as a power curve graph, presented here as Figure 1, which he named the "Long Tail" because though very few topics or items interested everyone, the number of special, specific, or idiosyncratic topics or items that interested anyone was very long. He also noted that the area of under the curve for special, specific, or idiosyncratic topics or items comprising this "tail" was greater than the area under few items of common interest, a discrepancy that he proposed indicates greater wealth could be generated by fulfilling the aggregate of special, specific, or idiosyncratic topics or items than had been generated fulfilling the common ones. The success of online retailing giants such as Amazon and Alibaba, companies that thoroughly utilize computer-mediated technologies, is roughly based upon this concept, one which might also underpin the success of Individuated Media companies.

\section{FIGURE 1 \\ MAJOR U.S. NEWSPAPERS' ONLINE TRAFFIC AND CALCULATED AVERAGE USER BEHAVIOR}

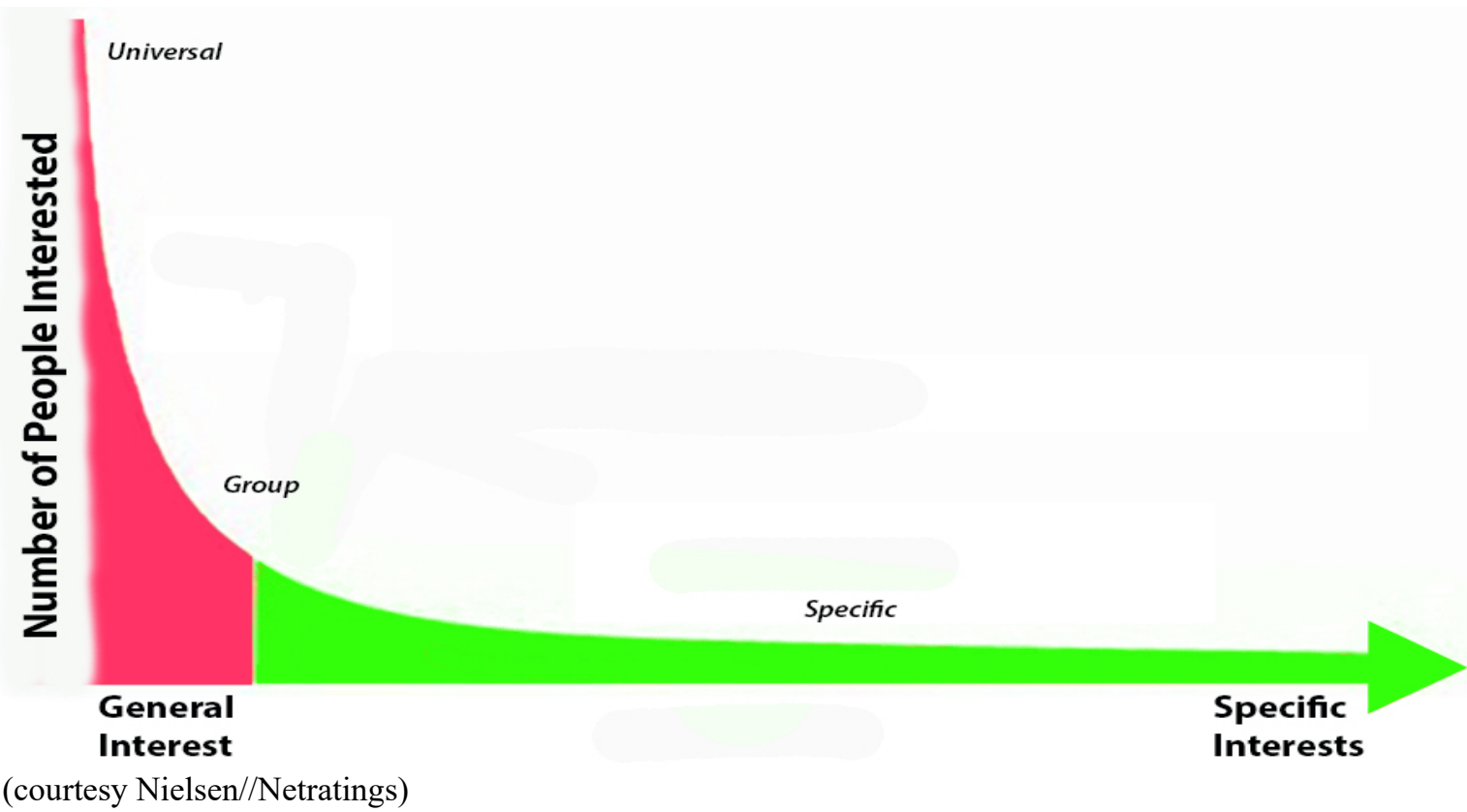

Ironic to their explosive success in the media environment, Individuated Media companies weren't initially designed or founded to compete with Mass Media companies. For examples, Google began as a webpage ranking experiment by two doctoral students in computing at Stanford University who, when their experiment succeeded, founded the company to sell their algorithmic software to other companies. During Google's first few years, they were then surprised by the unexpected consumer traffic using their software demonstration website, but the founders of Google were averse to earning ancillary revenues by selling online advertising space on that website. They ultimately did and its advertising revenues during 2020 generated US\$147 billion of Google's US\$181 billion overall turnover that year (Alphabet, Inc., 2021). 
YouTube, nowadays the world's largest on-demand video sharing website, which is now producing video its own commercial entertainment contents, as well as offering services for consumers who want to cancel cable television, was founded during 2005 as a video date ranking website. Facebook was created during 2003 as Facesmash.com, a college student profile photo rating website. Only when it quickly became extraordinarily popular among U.S. college students and was renamed Facebook did its founder Mark Zuckerberg consider selling advertising space on it. Advertising revenues now generate most of Facebook's US\$86 annual revenues (Facebook Inc., 2021). None of these Individuated Media companies were initially designed or founded to compete against Mass Media industries, yet they do and now dwarf those audiences and revenues.

\section{CONCLUSIONS}

Mass Media industry sectors in some nations are now claiming that Individuated Media companies have 'stolen' their advertisers and consumers. Some demand that their national government legislate or regulate that the most dominant Individuated Media companies be forced to share revenues with those Mass Media sectors. Although some Individuated Media companies might have become so large as to warrant anti-monopoly examination and regulation, the history of the market clash between Mass Media and Individuated Media companies belies the formers' sectoral claim that the latter 'stole' advertisers or consumers. During the first approximately 15 years of this century, Mass Media companies avidly let Individuated Media companies freely hyperlink and abstract their contents. The Mass Media companies' myopic hopes were that doing so would generate consumers traffic to their own websites. The Mass Media companies received that consumer traffic, but it didn't stick, for many of the reasons outlined in this paper. Mass Media companies lost consumers and hence advertisers to Individuated Media companies by the choice of those consumers and advertisers, who found Individuated Media services more efficient for their own purposes. The audience and revenue losses Mass Media companies have suffered trying to compete with the rise of Individuated Media were due to the myopia of Mass Media companies' in not foreseeing that the greatest potential of computer-mediated technologies was those technologies' algorithmic abilities to improvements to the selection of contents fed to individual consumers and was not those technologies' mere wired delivery of contents to consumers.

As the Informational Era supersedes the Industrial Era, the rise of Individuated Media services has ravaged Mass Media products and services and will continue to do so, due to Individuated Media services' superior capabilities to better match contents to consumer's individual mixes of needs, interests, tastes, and beliefs. Individuated Media won't disappear. Consequently, the Mass Media industries have become financially weakened, making them more difficult to adapt to the changes in the media environment that the rise of Individuated Media has wrought. Can the Mass Media industries continue? Will their production models of selecting and packaging contents according to surmisals about mass demographics such as location, gender, age, and general-interests or topical interests, compete successfully with Individuated Media services that aggregate, select, and package contents according not only those demographic factors but also each recipient consumer's expressed, recorded, or live online action, 'Like', search, and response? Can the Mass Media industries viably continue also to compete with Individuated Media services which target advertising that way? If billions of consumers are switching their media consumption habits from Mass Media products or services and to Individuated Media feeds, are their ways and means to adapt the Mass Media industries' infrastructure and creative resources to pivot and plug remuneratively into the Individuated Media industries? Using what traditional or new business models? These are some of the strategic media management challenges that nowadays need to be answered those as media technologies progress. And this has been an introductory paper about Individuated Media. 


\section{ENDNOTES}

1. Subsequent Personalized Media conferences [Denver, 2008; Washington, D.C.; 2009] were renamed Individuated Media conferences.

2. In most cases, the website's Home page and webpages that contain a single story.

3. Although analog printing presses cannot mass produce individuated contents, digital printing presses, which are basically giant ink jet printers controlled by computer-mediation, can. For examples, banks and credit card companies mass produce and postal mail monthly statements to more than 2.5 billion people worldwide, and each such statement contains is an individuated financial statement based upon that individual's own spending, finances, etc.

\section{REFERENCES}

Alphabet, Inc. (2021, February 2). Alphabet Announces Fourth Quarter and Fiscal Year 2020 Results. Retrieved from https://abc.xyz/investor/static/pdf/2020Q4_alphabet_earnings_release.pdf

Anderson, C. (n.d.). The Long Tail in a Nutshell. The Long Tail. Retrieved from https://longtail.typepad.com/about.html

Auxier, B., \& Andereson, M. (2021, April 7). Social Media Use in 2021. Pew Research Center: Internet \& Technology. Retrieved from https://www.pewresearch.org/internet/2021/04/07/social-mediause-in-2021/

Chyi, H., \& Ng, Y. (2020). Still Unwilling to Pay: An Empirical Analysis of 50 U.S. Newspapers' Digital Subscription Results. Digital Journalism, pp. 526-547.

Crosbie, V., \& Jansen, A. (2007). Proceedings of the Beyond the Printed Word Conference. Beyond the Printed Word. Vienna: World Association of Newspapers/Ifra

Dean, B. (2021, April 2). Social Network Usage \& Growth Statistics: How Many People Use Social Media in 2021? Backlink. Retrieved from https://backlinko.com/social-media-users

Facebook Inc. (2021, January 27). Facebook Reports Fourth Quarter and Full Year 2020 Results. Facebook. Retrieved from https://investor.fb.com/investor-news/press-releasedetails/2021/Facebook-Reports-Fourth-Quarter-and-Full-Year-2020-Results/default.aspx

He, A. (2019, July 30). eMarketer's July Earnings Recap: Facebook, Amazon, Google, Twitter, Snapchat, Netflix. eMarketer. Retrieved from https:/content-na1.emarketer.com/emarketer-july-earningsrecap-facebook-amazon-google-twitter-snapchat-netflix?ecid=nl1001

Horrocks, P. (2009). The End of Fortress Journalism. The Future of Journalism: Papers from a Conference Organized by the BBC College of Journalism (p.8). London: BBC College of Journalism.

Internet World Stats. (2019). Internet Usage Statistics: The Big Picture. Retrieved from https://internetworldstats.com/stats.htm

Liao, R. (2021, January 5). Alibaba shuts down 12-year-old music streaming app Xiami.

TechCrunch.com. Retrieved from https://techcrunch.com/2021/01/04/alibaba-discontinues-xiami/

Negroponte, N. (1995). Being Digital. New York: Alfred A. Knopf.

News Media Alliance. (2020, November 16). Big Tech Says Publishers Keep Majority of Ad Revenue, But Experience Suggests Otherwise. Retrieved from https://www.newsmediaalliance.org/google-adrevenue-op-ed-70-

percent/\#: :text=This\%20overwhelming\%20dominance $\% 20$ allows $\% 20$ Google,to $\% 20$ access $\% 20$ or $\% 20$ benefit $\% 20$ from

Newspaper Association of America. (2007). NADBase, Combined Home and Work, Six Month Average March-August.

Noam, E.M. (2018). Managing Media and Digital Organizations. Cham, Switzerland: Palgrave Macmillan.

Peters, J.W. (2011, March 17). The Times Announces Digital Subscription Plan. The New York Times. Retrieved from https://www.nytimes.com/2011/03/18/business/media/18times.html 
Schwartz, E.I. (1997). Webonomics. New York: Broadway Books.

Shearer, E. (2018, December 10). Social media outpaces print newspapers in the U.S. as a news source. Pew Research Center. Retrieved from https://www.pewresearch.org/fact-tank/2018/12/10/socialmedia-outpaces-print-newspapers-in-the-u-s-as-a-news-source/

Spotify Inc. (2021, April 14). Spotify Company Info. Retrieved from https://newsroom.spotify.com/company-info/

The New York Times Company. (2021, March 19). The New York Times Company 2020 Annual Report. Retrieved from https://nytco-assets.nytimes.com/2021/03/Final-NYT-2020-Annual-Report.pdf

Vandevanter, P. (2007). Proceedings of the Personalized MEdia Conference. Personalized MEdia Conference. Leipzig: NOW MEdia.

Vandevanter, P. (2008). Proceedings of the 2008 Individuated Media Conference. Individuated Media Conference. Denver: NOW MEdia.

Vandevanter, P. (2009). Proceedings of the 2009 Individuated Media Conference. Individuated Media Conference. Washington, D.C.: NOW Media.

60 Journal of Strategic Innovation and Sustainability Vol. 16(4) 2021 